\title{
Academische vorming in het medisch curriculum: noodzaak of luxe?
}

\author{
G.J. van der Vusse, R.M.F.M. Leclercq, J.M.H. op 't Root, A.C. Nieuwenhuijzen Kruseman
}

\section{Samenvatting}

Aandacht voor academische vorming binnen de universiteit neemt de laatste jaren sterk toe. Ook in het "Raamplan Artsopleiding 2009" wordt expliciet aandacht besteed aan dit onderwerp. Omdat academische vorming niet in een krachtige definitie te vangen is, hebben wij drie belangrijke domeinen van academische vorming binnen het curriculum geneeskunde geïdentificeerd en in onderdelen uitgewerkt om implementatie te vergemakkelijken.

Het eerste domein betreft dat van de Doener: opleiding tot wetenschappelijk onderzoeker, het tweede van de Denker, waarin scholing in wetenschapsfilosofie, kennisleer, geschiedenis van de wetenschap en de geneeskunde, en medische ethiek en recht op de voorgrond treedt; het derde heeft betrekking op de basisarts als Docent, die geschoold is in communicatie met de patiënt, collegae en studenten, en aandacht besteedt aan de Grote Conversatie. Op het grensvlak van deze domeinen bevinden zich elementen als verantwoordelijkheid, reflectie, eerlijkheid en fraude, en taalvaardigheid. Voorts wordt aandacht besteed aan mogelijkheden de te onderscheiden elementen in het curriculum geneeskunde te realiseren en aan problemen die daarbij kunnen rijzen. (Vusse GJ van der, Leclercq RMFM, Root JMH op 't, Nieuwenhuijzen Kruseman AC. Academische vorming in het medisch curriculum: noodzaak of luxe? Tijdschrift voor Medisch Onderwijs 2011;30(6):315-323.)

\section{Inleiding}

Regelmatig komt in Nederland de vraag aan de orde in welke mate universitair onderwijs garant staat voor academische vorming en of iemand die aan een universiteit is afgestudeerd ook over een academische attitude beschikt. ${ }^{1-5}$ Deze vraag wordt niet alleen gesteld om het onderscheid tussen universitaire en HBO opleidingen te accentueren, maar om ook het evidente belang van academische vorming aan de orde te stellen. In het Raamplan Artsopleiding 2009 wordt academische vorming uitgewerkt als onderdeel van het medisch curriculum met sterke nadruk op de arts als wetenschappelijk onderzoeker. ${ }^{6}$ In de afgelopen jaren hebben meerdere medische faculteiten academische vorming opgenomen in het medisch curricu- lum. ${ }^{4}{ }^{7}$ Eveneens is het vermeldenswaard dat de Nederlandse Vereniging voor Medisch Onderwijs (NVMO) een werkgroep ingesteld heeft, die ook academische vorming thematiseert.

Bij deze hernieuwde belangstelling voor academische vorming kan de vraag gesteld worden of academische vorming in het verleden een belangrijk onderdeel van de opleiding tot (basis)arts was en in welke periode de aandacht hiervoor is verslapt. De indruk bestaat dat in de jaren zestig van de vorige eeuw, deels door de democratisering van het hoger onderwijs, die er toe geleid heeft dat het aantal studerenden snel steeg, deels door de roep vanuit een groep politiek actieve studenten om het hoger onderwijs meer maatschappijbewust te maken, ook de opleiding Ge- 
neeskunde op een meer rationele leest geschoeid werd, hetgeen ten koste ging van de inbreng van de Humaniora in het medisch curriculum. ${ }^{8}$ Het nutsdenken trad vanaf die tijd steeds meer op de voorgrond. In dit tijdschrift is enige jaren geleden op indrukwekkende wijze door Derkse een lans gebroken voor de restauratie van algemene vorming in universitaire opleidingen omdat de 'vruchtbare nutteloosheid' ervan kan bijdragen aan een verruiming van de eigen reflectiehorizon. ${ }^{9}$

Het begrip academische vorming is moeilijk in een krachtige definitie te vangen. De vraag is of een poging daartoe tot meer helderheid zal leiden. Immers, een definitie stelt vast, omkadert, includeert en excludeert daarmee ook. Exclusie kan leiden tot het uit zicht raken van aspecten die door anderen, eventueel in een ander tijdsgewricht, als essentieel worden ervaren. Hoewel academische vorming niet eenduidig te definiëren is en in beschouwingen over dit onderwerp verschillend gedacht wordt over de essentie van academische vorming, over het onderscheid tussen academische en wetenschappelijke vorming en over de opgestelde criteria, zijn het laatste decennium door diverse auteurs waardevolle bijdragen geleverd aan de discussie over de wenselijkheid van het introduceren van academische vorming. ${ }^{19-10}$ Niet alleen zijn ontwerpers van medische curricula expliciete aandacht gaan besteden aan academische vorming, ook bij de drie Nederlandse Technische Universiteiten werd een sterke behoefte gevoeld academische vorming een plaats te geven binnen hun ingenieursopleidingen. Hiertoe werden zeven competentiegebieden geformuleerd met te onderscheiden criteria voor het bacheloren masterniveau. ${ }^{11}$ Wat betreft geneeskunde komt daar een derde niveau bij, het niveau van de basisarts. Regel is echter dat een student geneeskunde zich richt op het artsexamen en op de functie als arts. Daarom lijkt het ons voor het medisch curriculum alleen relevant om criteria te formuleren op het niveau van het artsexamen.

Om een programmatische uitwerking te faciliteren hebben wij de kerncompetenties herrangschikt en de, naar onze mening, expliciet te onderscheiden elementen van academische vorming zichtbaarder gemaakt. Het resultaat voor de geneeskunde is een beschrijving van academische vorming vanuit het perspectief van:

- De Doener: de arts als wetenschapper die over het nodige gereedschap beschikt om actief deel te nemen aan wetenschappelijk onderzoek en in staat is resultaten van wetenschappelijk onderzoek naar waarde te beoordelen en in de praktijkcontacten met de patiënt toe te passen.

- De Denker: de professional die reflecteert op wetenschap in het algemeen en op geneeskunde in het bijzonder, die ethische en juridische aspecten van de geneeskunde weet te doorgronden, en die doordrongen is van de persoonlijke en maatschappelijke verantwoordelijkheden van de universitair opgeleide arts.

- De Docent: de onderwijzer die in staat en bereid is om kennis over te dragen aan patiënten, collegae, en leerlingen, maar ook 'Het Verhaal' doorgeeft aan anderen en deel weet te nemen aan 'de Grote Conversatie', een volgens Kronman reeds lang geleden ingezette en nog steeds voortdurende conversatie over de belangrijke kwesties van het leven. ${ }^{12}$

Waar deze drie domeinen elkaar overlappen, komen aspecten voor als verantwoordelijkheid, reflecteren op de eigen rol als arts en wetenschapper, eerlijkheid en fraude, ontwikkeling van een persoonlijke leerstrategie en het beschikken over bovengemiddelde taal- en didactische vaardigheden. ${ }^{1}$ In Figuur 1 worden deze drie 
domeinen als deels overlappende cirkels weergegeven. Hun onderlinge begrenzing is vager dan in de figuur wordt gesuggereerd en de grootte van de cirkels zal per persoon verschillen.

\section{Het domein van de Doener}

De moderne geneeskunde is het product van intensief wetenschappelijk onderzoek gedurende tal van jaren. Dit werk is nooit af. Voortdurend wordt bestaande kennis vervangen op basis van door wetenschappelijk onderzoek verworven nieuwe inzichten en technische mogelijkheden. De arts speelt als onderzoeker in dit proces een essentiële rol. Dit maakt een opleiding tot wetenschappelijk onderzoeker in het medisch curriculum tot topprioriteit. De arts die zelfstandig wetenschappelijk onderzoek verricht, of daar op adequate wijze in kan participeren, is een essentiële schakel in de vertaling van zorgvragen in wetenschappelijk onderzoek en in de toepassing van resultaten daarvan in de praktijk. Ook indien een arts niet actief in wetenschappelijk onderzoek participeert, spreekt en verstaat hij of zij de taal van de wetenschap. Essentieel hierbij is kennis van onderzoeksmethoden, met name epidemiologie en medische statistiek, en het vermogen om door kritisch lezen van de medischwetenschappelijke literatuur een afweging te maken of nieuwe kennis en methodieken voldoende uitgekristalliseerd zijn voor toepassing in de praktijk.

\section{Het domein van de Denker}

Het domein van de Denker wordt wel als academische vorming in strikte zin beschouwd omdat activiteiten in dit domein bij uitstek zullen leiden tot een academische attitude. In tegenstelling tot het do-

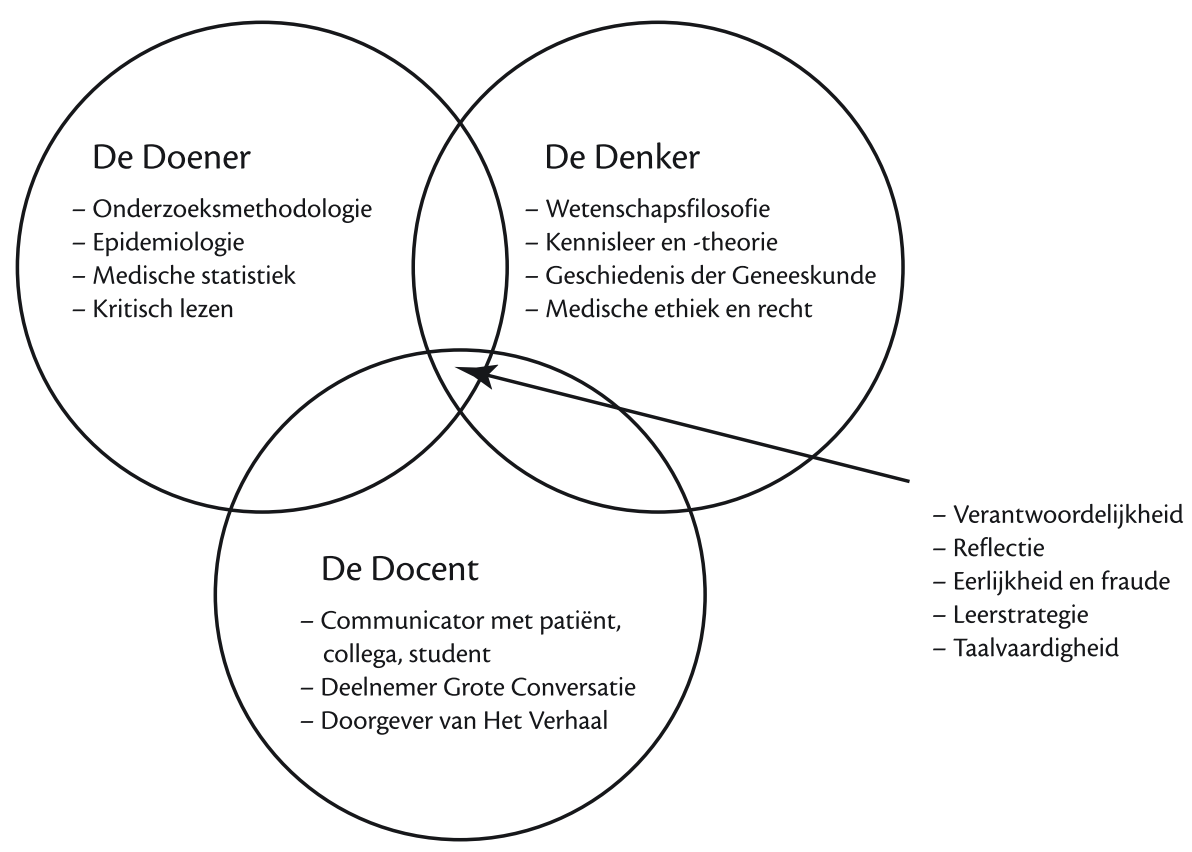

Figuur 1. Venn-diagram met de drie domeinen van academische vorming: de Doener, de Denker en de Docent. 
mein van de Doener is bij de Denker minder nauwkeurig aan te geven welke elementen tot dit domein behoren. Ook anderen hebben met dit probleem geworsteld. ${ }^{2}$ Dat maakt echter het domein niet minder relevant en de aandacht ervoor niet minder urgent. De teloorgang van de Humaniora aan de Nederlandse universiteiten maakt dit probleem nijpender. Een poging dit domein te omschrijven in plaats van exact te definiëren heeft tot voordeel dat er ruimte gecreëerd wordt voor persoonlijke invulling door de docent én de student.

Inzicht in wetenschapsfilosofie, wetenschapsleer en kennistheorie behoort tot dit domein. Belangrijke vragen die zich daarbij voordoen zijn: Het is evident dat wetenschap in hoog aanzien staat, maar wat is wetenschap eigenlijk? Wat is het bijzondere aan wetenschap en aan haar methoden? Waarop is de autoriteit van de wetenschap gebaseerd? Met dit inzicht zal de pas afgestudeerde arts in een wereld van argumenten voor en tegen, (on)zekerheden en overtuiging, objectivisme en constructivisme, evidentie en empirie uiteindelijk opmerkzaam, vindingrijk en kritisch zijn of haar positie bepalen.

Ook inzicht in de geschiedenis van de wetenschap, en specifiek van de geneeskunde, is hiertoe belangrijk. ${ }^{13}$ Het laat zien wie bijgedragen heeft aan geneeskundige kennis en op welke wijze. Inzicht in de geschiedenis van wetenschap en geneeskunde draagt ook bij aan het vermogen begrip te tonen voor de grenzen en de betrekkelijkheid van geneeskundige kennis. Het leert te leven en te werken met onzekerheden.

Medische ethiek en gezondheidsrecht zijn eveneens belangrijke aspecten van academische vorming. Allereerst is er de unieke en individuele patiënt met zijn of haar medische hulpvraag en de afweging van de arts wat goed, juist en rechtvaardig voor hem of haar is. Zaken als wat medisch mogelijk is, welke alternatieven er zijn en wat de vigerende juridische en maatschappelijke opvattingen zijn, spelen ook een rol. Het zijn onderwerpen die de student zich eigen maakt om te kunnen reflecteren op de meest essentiële zaken van de geneeskunde en daarin een eigen positie in te nemen. Hierdoor leert de arts de ethische grondslagen van het beroep, en wordt hij of zij zich ervan bewust dat ethische en juridische normen en systemen niet alleen gebonden zijn aan de samenleving en gezondheidszorg maar ook aan persoonlijke belangen, mogelijkheden en waardesystemen.

\section{Het domein van de Docent}

Het derde domein, de Docent, wordt gekarakteriseerd door de arts die informatie weet te vergaren via literatuur, een luisterend oor en open dialoog én kennis weet over te dragen aan anderen. De docent weet in voor de patiënt begrijpelijke termen uit te leggen en te bespreken wat het medische probleem is, wat de therapeutische mogelijkheden zijn en welke verantwoordelijkheden de patiënt zelf heeft in zijn of haar ziekte. De docent weet ook aan de hand van eigen inzichten en als rolmodel voor studenten een faciliterende rol te spelen bij het conceptualiseren van complexe problemen. ${ }^{19}$ Op metaniveau betreft het hier de arts die deel kan nemen aan het maatschappelijk debat over zijn beroep en de Grote Conversatie. ${ }^{12}$ Deze Conversatie wordt gevoerd zowel door dichters, romanschrijvers en kunstenaars alsook door wetenschappers, inclusief historici en filosofen. De student is te beschouwen als een laatkomer in deze conversatie, leert hier veel van en kan een bijdrage leveren. Ook is de docent de spil in het doorvertellen van Het Verhaal, het 
Verhaal waarvan het zo belangrijk is dat het verteld blijft worden, omdat 'Science and Medicine fundamentally story telling activities' zijn. ${ }^{14}$

\section{De grensvlakken van de drie domeinen}

In het gebied van de elkaar overlappende cirkels van de Doener, de Denker en de Docent, bevinden zich elementen als:

- Het nemen van verantwoordelijkheid. ${ }^{15}$ Elke afgestudeerde arts heeft inzicht in het begrip verantwoordelijkheid en is zich bewust van zijn verantwoordelijkheid ten aanzien van patiënten, zichzelf als hulpverlener en zijn of haar taak ten behoeve van de samenleving. Deze verantwoordelijkheid is ondermeer gebaseerd op een gedegen inzicht in en reflectie op ethische aspecten van zijn of haar professionele handelen, en op analyse van informatiebronnen, meningen/ opvattingen, etc.

- Het vermogen tot reflectie op eigen functioneren als wetenschappelijk onderzoeker en als uitvoerder van wetenschappelijk verkregen kennis.

- Aspecten als eerlijkheid, vrij zijn van vooringenomenheid, onderkennen en uitbannen van fraude, het weerstand bieden tegen plagiaat en eer toekennen aan wie ere toekomt. ${ }^{16}$

- Het ontwikkelen van persoonlijke leerstrategieën omdat de geneeskunde niet af is bij het behalen van het basisartsdiploma. Het is een gebied dat voortdurend in beweging is en gekenmerkt wordt door een snelle ontwikkeling van kennis en kunde.

- Het aanleren van en beschikken over een goede taalvaardigheid, zowel mondeling als schriftelijk. Een hoge mate van taalvaardigheid is niet alleen van belang voor het contact met de patiënt, maar ook voor discussies met vakgenoten en het doorvertellen van ervaringen.
Hierbij is uiteraard de landstaal belangrijk maar ook een goede beheersing van het Engels, een taal die uitgegroeid is tot de lingua franca van de moderne wetenschap.

\section{Implementatie en afsluitende overwegingen}

De hamvraag die gesteld kan worden is of hernieuwde aandacht in het medisch curriculum voor academische vorming ook leidt tot betere artsen, artsen die in staat zijn tegemoet te komen aan de hoge eisen die zijzelf en de maatschappij stellen bij de uitoefening van de geneeskunst. We wagen een poging om deze vraag te beantwoorden. We stellen vooraf dat academische vorming, met de drie te onderscheiden domeinen van de Doener (de wetenschapper), de Denker (de academicus) en de Docent (de onderwijzer), alleen te realiseren is als zij is gestoeld op een hecht fundament, dat wil zeggen een medisch curriculum met aandacht voor het aanleren van voor een basisarts gewenste medische kennis en kunde. Terecht wordt in het Raamplan Artsopleiding 2009 ruim aandacht besteed aan dit fundament en worden richtlijnen geformuleerd om dit te realiseren. Naar onze overtuiging zal een dergelijk sterk fundament aangevuld met academische vorming in de meest brede zin van het woord leiden tot betere artsen. Artsen zijn dan in staat om een zinvolle bijdrage te leveren aan het vermeerderen van wetenschappelijk kennis en methodieken, deze beide aspecten op hun merites te beoordelen en na weging toe te voegen aan hun theoretisch en praktisch instrumentarium. Zij zijn beter opgewassen tegen de eisen die de maatschappij en ook zij zelf stellen aan het uitoefenen van de geneeskunst in een complexe en steeds veranderende wereld, waarin persoonlijke verantwoordelijkheid en ethisch verantwoord handelen 
essentieel zijn. Tevens zal het ertoe leiden dat de arts zich geëquipeerd acht om deel te nemen aan het politiek-economische discours over de gezondheidszorg. Tenslotte zullen zij, zoals helder verwoord door Martha Nussbaum in haar beschouwing over academische vorming van studenten aan Angelsaksische universiteiten, zich ontwikkelen tot volwaardige leden van een steeds complexer wordende samenleving. ${ }^{17}$

Als overeenstemming bereikt wordt over de vraag of academische vorming een essentieel onderdeel van het medisch curriculum is, dringen zich tenminste twee nieuwe vragen op die een duidelijk antwoord behoeven: hoe wordt academische vorming, im- of expliciet, in het curriculum gestalte gegeven en hoe wordt academische vorming getoetst? Uitgaande van de te onderscheiden elementen uit het Venn-diagram kunnen de volgende aanbevelingen worden gedaan.

\section{Het domein van de Doener}

De grondbeginselen van wetenschappelijke vorming (het domein van de Doener) kunnen ondermeer aangeleerd worden aan de hand van een databestand waarin gegevens opgeslagen zijn die verkregen worden tijdens practica in de bachelorfase waarbij de studenten onderzoek doen bij zichzelf. Een willekeurig voorbeeld hierbij is een practicum Spirometrie waarbij gegevens over longvolumina, piekstroom, Tiffaneau index, etc. worden verzameld. Niet alleen ervaart de student wat het betekent om zelf een lichamelijk onderzoek te ondergaan, ook leert hij/zij een databestand op te bouwen waarin gegevens van de gehele jaargroep worden opgeslagen en beschikbaar zijn voor nader onderzoek. Aan de hand van onderzoeksvragen die door de studenten zelf geformuleerd worden, kunnen de data gebruikt worden, waarbij ook onderricht in medische statistiek een plaats kan krijgen. De onderzoeksresultaten worden beschreven in meerdere scripties waardoor geoefend kan worden in schriftelijke taalvaardigheid. Het is essentieel dat deze scripties zowel vormtechnisch als inhoudelijk door deskundigen beoordeeld worden, waarna beide aspecten worden besproken. Persoonlijke feedback is cruciaal voor de wetenschappelijke vorming van de student. In de masterfase kan wetenschappelijke vorming verder gestalte krijgen in een uitgebreide wetenschapsstage. Toetsing vindt plaats in de vorm van continue feedback op de vorderingen die de student maakt betreffende het formuleren van een onderzoeksvraag, opzetten van een onderzoeksprotocol, uitvoeren van onderzoek, analyseren van de verkregen resultaten en mondelinge alsook schriftelijke verslaglegging. Het verkrijgen van epidemiologische kennis kan door de jaren heen plaatsvinden in kleinschalig onderwijs ondermeer via Critical Appraisal of a Topic (CAT). Hierbij bespreken studenten in koppels van twee een wetenschappelijk artikel met aandacht voor onderwerpen als selectiebias, sensitiviteit/specificiteit, gouden standaard, etc. Toetsing van hun vorderingen op dit gebied vindt plaats door vakdocenten, bij voorkeur in de vorm van persoonlijke feedback aan de hand van een schriftelijke CAT opdracht.

\section{Het domein van de Denker}

Belangrijke elementen van het domein van de Denker, wetenschapsfilosofie, kennisleer en kennistheorie lenen zich niet goed voor grootschalige colleges. Eerder dient gedacht te worden aan kleinschalige 'socratische lessen' waarbij persoonlijk contact tussen docent en student gegarandeerd is. Deze lessen zijn blok- en themaoverstijgend en worden regelmatig in de bachelorfase gegeven. Toetsing kan plaatsvinden in de vorm van essays die de stu- 
dent individueel schrijft en zowel vormtechnisch als inhoudelijk beoordeeld worden met een persoonlijk terugkoppeling naar de student. De geschiedenis van de geneeskunde zou, indien beschikt wordt over bevlogen docenten met grote didactische gaven, gedoceerd kunnen worden in capita selecta-achtige, grootschalige colleges. Deze colleges leren de student informatie op te doen uit het gesproken woord, waarbij de vakdocent een rolmodel is voor de student betreffende het verzorgen van een lezing voor een groot publiek. Toetsing van het kennisniveau van de student kan plaatsvinden middels een tentamen bestaande uit open vragen. Multiple choice tentamens zijn minder geschikt als toetsmiddel. Daarnaast kan gedacht worden aan het schrijven van essays, beoordeeld met persoonlijke feedback aan de student door de vakdocent. Kleinschalig onderricht in medische ethiek en recht lijkt het best verzorgd te kunnen worden tijdens de coschappen in de masterfase van het curriculum, omdat dan aangesloten kan worden bij de belevingswereld van de student. De thema's van de discussiegroepen kunnen door de studenten zelf aangereikt worden, maar ook ingebracht worden door de vakdocent op basis van hun actualiteit. Toetsing van de persoonlijke ontwikkeling van de student op dit gebied kan plaatsvinden door middel van het schrijven van essays of het houden van een voordracht voor de peergroep.

\section{Het domein van de Docent}

Een aantal aspecten komt impliciet tot hun recht in curricula die gebaseerd zijn op probleemgestuurd onderwijs (PGO). Kleinschalig onderwijs in onderwijsgroepen leidt ertoe dat de student leert luisteren naar de ander, op heldere wijze standpunten formuleert en communiceert, en respectvol omgaat met opvattingen van zijn/ haar medestudenten. Toetsing vindt plaats in een persoonlijke beoordeling door de onderwijsgroepsleden en de tutor/stafmedewerker. Tijdens de bachelorfase kan communicatie geoefend met en beoordeeld worden door simulatiepatiënten en collega-studenten in een Skillslab omgeving. Tijdens de masterfase wordt deze mogelijkheid geboden in de coschappen onder voorwaarde van een veilig klimaat voor het geven en ontvangen van feedback. De student gevoelig maken voor de narratieve aspecten van de wetenschap in het algemeen en de geneeskunde in het bijzonder en deelname aan de Grote Conversatie is een impliciete taak van de wetenschappelijke en klinische staf tijdens het vervullen van hun onderwijs- en begeleidingsrollen. Expliciete summatieve toetsing van de student is hierbij niet aan de orde.

\section{Op het grensvlak van de drie domeinen}

Veel zaken die zich bevinden op het grensvlak van de drie domeinen zijn al de revue gepasseerd. Het aanleren van taalvaardigheid zowel in de landstaal als in het wetenschappelijk Engels vindt plaats via het schrijven van essays en het houden van voordrachten door de student gedurende het gehele curriculum. Ook voor het aanleren van een leerstrategie, die de student in staat stelt om 'education permanente' in de praktijk te realiseren, dient een impliciete plaats in het curriculum ingeruimd te zijn. Als onderdeel van onderricht in Medische ethiek en recht en de CAT kan aandacht beteed worden aan 'eerlijkheid en fraude'. Ook is het aan te bevelen om tijdens de coschappen tijd in te ruimen voor het bespreken van actuele uitspraken van de Medische tuchtcolleges. Het toetsen van individuele voortgang op dit gebied kan plaatsvinden middels een beoordeling van voordrachten van de student voor zijn/haar peergroep en van es- 
says. Reflectie op de diverse rollen die de basisarts speelt binnen de wetenschap en de geneeskunde zal in belangrijke mate gestimuleerd worden door stafmedewerkers die weten dat zij een rolmodel zijn voor hun studenten. Ten slotte 'verantwoordelijkheid': naast het feit dat elementen hiervan in vrijwel alle andere aspecten en onderwijsmomenten zijn terug te vinden, overstijgen ze deze ook.

Het streven naar universitair opgeleide artsen met een academische attitude is op dit moment echter niet eenvoudig te realiseren. Academische vorming betekent intensivering van het onderwijs en uitbreiding van het aantal stafmedewerkers. In het huidige politieke klimaat staan echter studieduurverkorting, marktwerking, efficiency en bezuinigingen op de onderwijsformatie hoog op de agenda. Dit, in combinatie met een gestaag stijgend aantal jongeren dat aan de poorten van de universiteit klopt om toegelaten te worden, zet academische vorming in het medisch curriculum ernstig onder druk.

\section{Tot slot}

Academische vorming staat en valt bij de actieve participatie van zowel de vakdocent als de student. De ideale vakdocent beschikt zelf over een academische attitude omdat zij of hij, hoe dan ook, een rolmodel is in de basisartsopleiding. Docentprofessionalisering helpt daarbij, maar voor de vakdocent blijven een natuurlijke grondhouding, enthousiasmerende inzet en gedegen en brede kennis van zijn/haar eigen vakgebied en daarbuiten essentieel. ${ }^{18-19}$ Tevens is een universitair carrièrebeleid, dat ook op onderwijs toegesneden is, hoogst noodzakelijk maar veelal niet aanwezig.

Academische vorming is geen activiteit die achteroverleunend in de collegebank gerealiseerd wordt: intrinsieke motivatie van de student is een voorwaarde om zich academisch te laten vormen en zich een academische attitude eigen te maken. Niet bij elke student zal academische vorming een warm onthaal krijgen, maar studenten de mogelijkheid onthouden om zich academisch te vormen is geen acceptabel alternatief. De voor ons retorische vraag: "Wie zou niet bij een dergelijke wereld willen horen, een wereld waar een brede wetenschappelijke, maatschappelijke, sociale en culturele vorming geboden wordt?" is hierbij duidelijk van toepassing. ${ }^{20}$ Een medische faculteit, die ingebed is in een universitaire gemeenschap waar patiëntenzorg, onderwijs en onderzoek verweven zijn en waar een scala aan opleidingen wordt aangeboden, is bij uitstek de plaats waar een dergelijke wereld gecreëerd wordt.

\section{Literatuur}

1. Schuyt C. De universiteit van Jankarel: Gevers als socioloog. In: Jankarel Gevers. De breekbaarheid van het goede. Amsterdam: Digitale Bibliotheek der Nederlandse Letteren: 1999. [The university of Jankarel: Gevers as a sociologist. In: Jankarel Gevers: The fragility of good].

2. Oost $\mathrm{H}$ et al. Naar een interpretatie van "Academische vorming”. in Mededelingen, O.e.S. Interfacultair instituut voor lerarenopleiding. Universiteit Utrecht: Utrecht; 1998. [Towards an interpretation of "academic education"].

3. De Klerk R, G de Reuver. Academische vorming als ijkpunt voor onderwijsinnovatie. [Academic education as benchmark of education innovation]. In: Bouwen aan Academisch Onderwijs. Verkenningen bij gelegenheid van het afscheid van professor Karel van Dam. M van den Bergh, R de Klerk, and G de Reuver, Editors. 2002: Amsterdam. p. 1-9.

4. Spierenburg E et al. Academische Vorming 2008, Rotterdam: Erasmus MC. [Academic Education].

5. Donkers $\mathrm{H}$ et al. Academische Vaardigheden Bedrijfswetenschappen, Radbout Universiteit, Editor 2007, Faculteit der Managementwetenschappen.: Nijmegen. [Academic skills and management sciences].

6. Van Herwaarden C, R van der Laan en R Leunissen, Raamplan Artsopleiding 2009. Utrecht: Ned Federatie UMC's; 2009. [The 2009 Framework for undergraduate medical education in the Netherlands].

7. Onderwijsvisitaties Geneeskunde, S. QANU, Editor 2004: Utrecht. p. 18. [Medical education site visit]. 
8. Veld R in 't. Marketing van universiteiten. In afscheidssymposium Vic Bonke, Universiteit Maastricht. [Marketing universities].

9. Derkse W. Vruchtbare "nutteloosheid": het belang van algemene vorming in de context van beroepsgerichte academische opleidingen. Tijdschrift voor Medisch Onderwijs 2004. 23(1): 57-63. [Fruitful 'irrelevance': the value of unrelated academic subjects in university courses for vocational trainng. [Netherlands Journal of Medical Education 2004; 23(1):57-63].

10. Noorda S. Vorming in het wetenschappelijk onderwijs. In: Essays over vorming in het onderwijs. Den Haag: Onderwijsraad; 2011. [General education in scientific education programme].

11. Meijers A, Van Overveld C, Perrenet J. Criteria voor de Academische Bachelor en Master Curricula., 2005, TU/e: Delft/ Eindhoven/Twente. [Criteria for the academic Bachelor and Master Curricula].

12. Kronman A. Education's End. Why Our Colleges and Universities Have Given up the Meaning of Life. Yale. University Press 2007, New Haven and London: Caravanbooks.

13. van Berkel K. De stem van de wetenschap. Vol. 1. 2008, Amsterdam: Bert Bakker.p. 676. [The voice of science].

14. DasGupta S, Charon R. Personal illness narratives: using reflective writing to teach empathy. Acad Med 2004; 79(4): 351-356.

15. Holdrinet R. Handreiking over verantwoordelijk samenwerken. Ned Tijdschr Geneeskd 2010;154(4): 155-156. [Help for responsible cooperation].

16. Taitsman J. Educating Physicians to prevent Fraud, Waste and Abuse. N Engl J Med 2011; 364(2):102103.
17. Nussbaum M. Democratic Education on the Ropes, in Not for profit. Why democracy needs humanities. 2010, Princeton University press: Princeton and Oxford. p121-143.

18. Stes A et al. Docentprofessionalisering in het Hoger Onderwijs: stand van zaken en toekomstperspectieven. [Faculty development in higher education]. In: De Universiteit in ontwikkeling., H. Verboven, Editor 2008, Pelckmans* Kapellen: Antwerpen.

19. de Leeuw P. De rol van (de) arts. Ned Tijdschr Geneeskd Stud 2008;11(2) 40. [The role of the doctor].

20. Procee $\mathrm{H}$. $<$ Het is niet zo $>-$ over deze bundel. Bij die wereld wil ik horen. [That is not how it is about this collection. That is the world I want to belong]. Zesendertig columns \& drie essays over de vorming tot academicus. Amsterdam: Boom; 2004.

\author{
De auteurs: \\ Prof dr. Ger J. van der Vusse is fysioloog. * \\ Drs. Raymond M.F.M. Leclercq is huisarts np. * \\ Dr. Jos M.H. op 't Root is andragoloog. * \\ Prof. dr. Arie C. Nieuwenhuijzen Kruseman is internist. * \\ * Allen zijn (oud)medewerkers van de Universiteit \\ Maastricht. \\ Correspondentieadres: \\ Ger J. van der Vusse, Vakgroep Fysiologie, FHML, Maas- \\ tricht University, PO 616, 6200 MD Maastricht. E-mail: \\ vandervusse@maastrichtuniversity.nl
}

Belangenconflict: geen gemeld

Financiële ondersteuning: geen gemeld

\section{Summary}

Increasing attention has been given to academic education in Dutch universities during the past decade. In medicine, academic education is incorporated in the "Raamplan Arts-opleiding 2009". Since academic education is difficult to capture by one conclusive definition, we have identified three domains of academic education in the medical curriculum and elaborated these domains to facilitate implementation. The first domain is that of the Doer: education in conducting scientific research; the second domain is that of the Thinker, dominated by philosophy of science, history of science and medicine, medical ethics and law; the third domain is that of the Teacher, who is able to communicate with his/her patients, colleagues and students and equipped to participate in the Great Conversation. At the intersections of these three domains we find aspects like responsibility, reflection, sincerity and fraud and linguistic skills. Attention is also paid to how these domains and aspects can be implemented in the medical curriculum and which potential difficulties are to be anticipated. (Vusse GJ van der, Leclercq RMFM, Root JMH op 't, Nieuwenhuijzen-Kruseman AC. Academic education in the medical curriculum: necessity or luxury? Netherlands Journal of Medical Education 2011;30(6):315-323.) 